\title{
A response to commentaries on modelling stakeholder perceptions of a new financial reporting system
}

\author{
Alexandra FONTES \\ Instituto Politécnico de Viana do Castelo, Portugal \\ Email: afontes@estg.ipvc.pt \\ Lúcia Lima RODRIGUES \\ GOVCOPP, University of Minho, Portugal \\ Email: Irodrigues@eeg.uminho.pt \\ Russell CRAIG \\ Portsmouth Business School \\ University of Portsmouth \\ Richmond Building, Portland Street \\ Portsmouth, Hampshire PO1 3DE \\ UK \\ Email: $\underline{\text { Russell.Craig@port.ac.uk }}$
}

\section{Corresponding Author:}

Alexandra Fontes

Superior School of Technology and Management, Department of Economics and Entrepreneurial Sciences

Polytechnic Institute of Viana do Castelo, Avenida do Atlântico, Apartado 574, 4901-908 Viana do

Castelo,

Portugal

Phone: (+00351) 258819700 / (+00351) 934253643 e-mail: afontes@estg.ipvc.pt

\section{ABSTRACT}

This is a response to questions raised by Kuruppu and Lehman (2016) and Thomson (2016) on Fontes, Rodrigues and Craig's (2016) model of Stakeholder Perceptions of a New Financial Reporting System. We clarify some matters that arise from the commentators' concerns about the intended contribution of the model, and its conceptual foundations. We also respond to concerns raised about the need to adopt a holistic and contextualized approach; provide further insights to the complex and dynamic nature of stakeholder perceptions and their formation; and elaborate on methodological assumptions underpinning the model. We argue that interpretative-based research offers an appropriate and challenging way to further improve and extend the model. We encourage researchers to adopt critical and interpretive-based methods to foster a reflective debate that will lead to improvements in the Stakeholder Perceptions model.

Key words: Theory Development; Grounded Theory; Perceptions; Change Processes. 


\section{Introduction}

This is a response to the commentaries by Kuruppu and Lehman (2016) and Thomson (2016), of Fontes, Rodrigues and Craig (2016) (henceforth referred to as FRC (2016)). In FRC (2016), we introduced a preliminary model of Stakeholder Perceptions of a New Financial Reporting System (henceforth, the "Stakeholder Perceptions" or SP model), recognized its limitations, and acknowledged the need for its further development.

The two commentaries are welcomed because they are likely to foster productive, critical and reflexive debate about the SP model. Their critical approach seems likely to yield benefits, in broader contexts, for theory development and model refinement. Indeed, the commentaries have prompted us to refine some conceptual foundations of the SP model, and to alert future researchers of the need for caution when considering methodological approaches to testing the SP model.

We did not purport to present a final model in FRC (2016). Rather, we presented a preliminary model composed of a set of propositions that needed to be assessed in different empirical contexts, preferably using an interpretative approach. We submit that the concerns raised in both commentaries stem from a mis-appreciation of the conceptual foundations of the model, and its expected contributions. Here we clarify those specific matters, elaborate on other aspects of FRC (2016), and offer some thoughts on how to develop the SP model further.

This reply is structured as follows. In Section 2, we clarify the objective and expected contribution of the SP model. Then, in Sections 3 to 6 we address the commentary of Kuruppu and Lehman (2016) specifically. In Sections 7 and 8 we reply to Thomson (2016), before offering some concluding remarks in Section 9.

\section{Research Objective: Towards Theorizing}

We begin by expanding on the proposed contribution of the SP model, stressing that the model represents the preliminary stage of theory development (the "theory borrowing" stage). The adoption of such an approach is crucial in addressing the lack of an established theoretical framework to explain stakeholders' perceptions of financial reporting processes. ${ }^{1}$

The theory borrowing approach used in FRC (2016) followed Oswick et al. (2011) by borrowing theories to construct a theoretical model that would explain stakeholders' perceptions of financial reporting processes. The SP model should be classified, in accord with Oswick et al. (2011), as a "novel travelling theory".2 Given its "novelty", subsequent application of the model in differing empirical contexts will enable it to be subject to sound critical evaluation. Accordingly, FRC (2016) argued that future empirical research is needed to generate an improved theory (i.e., a "radical travelling theory" in Oswick et al.'s (2011) terminology). Such further research would contribute to a holistic, enriched, and critical understanding of the model. We re-emphasize that FRC (2016) presented an initial model as a preliminary step in theory development. 
We support the use of an interpretative approach to critically assess the SP model in various empirical contexts: indeed, we regard this to be essential in fostering its development (Hopper and Powell, 1995; Armstrong, 2008; Parker, 2012). An interpretative approach has strong capacity to contribute to theory in general, including to financial reporting theory and practice. Specifically, we suggest that the grounded theory approach to qualitative research is particularly suited to assess and develop the SP model. Such a methodological approach implies a continuous fertilization/interaction of theory and data in which researchers are alert to the need for empirical flexibility, reflection and reflexivity. They must be conscious of the need to revise theory based on data, rather than offer a limited and restricted view based on a prior theoretical focus and preconceived position (Laughlin, 1995; Elharidy et al. 2008; Joannidès and Berland, 2008; Gurd, 2008; Vaivio, 2008). Exponents of grounded theory often regard prior theories as tentative. They seek to enrich emergent theory by modifying (or even disconfirming) existing propositions.

\footnotetext{
${ }^{1}$ The contribution of this initial model was acknowledged in $\operatorname{FRC}(2006, p .361$, italics applied), as follows: "The theoretical propositions represent first approximations of the phenomenon under scrutiny. Nonetheless, the model contributes to the development of financial reporting by borrowing different approaches, lines of research and theories (hitherto unconnected), to investigate stakeholders' perceptions of financial reporting change."

2 At this "novel" stage, researchers seek to provide "quirky", rather than broad and deep insights. We recognize that models such as SP "largely reinforce, build upon, or resonate with prior knowledge rather than offer a more critically oriented perspective" (Oswick et al., 2011, p. 324).
} 
The SP model does not purport to defend the legitimation of proposed financial reporting change. Rather, operationalization of the model is intended to provide insights and/or political messages to help overcome some obstacles to accounting reform. We provided some examples of these potential insights and messages (FRC, 2006, p.311-312). However, we did not imply receptiveness to, or uncritical acceptance of, International Financial Reporting Standards (IFRS). Operationalization of the SP model has strong potential to yield critical views about the adoption of IFRS, highlight conflicts of interest, and expose sources and forms of resistance to change. Application of the SP model may also generate practical insights that will promote and sustain the success of any change to IFRS. The model can also reveal potential sources and forms of resistance and conflict that will weaken pillars of support for global adoption of IFRS. The practical potential insights are not mutually exclusive. They are also subject to contextual differences (such as with respect to time, stakeholder group identities, and national context).

Attaining in-depth understanding of stakeholders' perceptions of financial reporting change has three important outcomes. First, it will provide regulators with critical understanding of the extent to which stakeholders were (or were not) empowered in the process of IFRS change. Second, it will foster broader community debate and involvement. This seems likely to lead different stakeholder groups to challenge different guidelines and opinions on the adoption of IFRS, and to highlight alternative ways of thinking about "international accounting obligations." Third, understanding of stakeholder perceptions will advance the public interest in the process of financial reporting change. By acknowledging the potential for conflicts and resistance to change, the SP model is capable of contributing well to re-assessments the role of accounting in organizational change and adaptation (Hopper and Powell, 1985).

In hindsight, we recognize that FRC (2016) probably overemphasized the constructive insights that were likely to arise from applying the model. These were insights that could be construed as promoting the success of financial reporting change. However, the ultimate goal of FRC (2016) was not to preserve and legitimize IFRS - as postulated in both commentaries. Rather, we stressed the importance of undertaking a "sympathetic adoption process" that would generate awareness among various interest groups, and thereby be conducive to acceptance and effective implementation of a new financial reporting system.

\section{Ethical Dimension of Financial Reporting Change}

We agree with Kuruppu and Lehman $(2016$, p. 316) that "to theorise change we must not only advance the interests and perceptions of stakeholders, but challenge the social structures that embed principles of neoliberalism." Additionally, we concur with their view that listening to 
stakeholders' voices will be conducive to challenging the "economic and neoliberal logic on which the accounting sphere relies ... [and will help] ... to appreciate the content of reasoning associated with international accounting obligations" (pp. 317-18). We strongly believe that exploring stakeholders' perceptions will foster dialogue and critical evaluation of whether IFRS are desirable and fair from a societal perspective. The SP model does not neglect the role of stakeholders in the process of financial reporting change (as also claimed by Thomson $(2016$, p. 320)). We agree that an emphasis on in-depth understanding of the perceptions and explanations of the targets of financial reporting change are likely to inform the contested/democratic political process of financial reporting: that is, "how participants (or agents) are empowered or disempowered in the process of change initiated by IFRS" (Kuruppu and Lehman, 2016, p. 317).

\section{Moral Dimension of Financial Reporting Change}

We agree with Kuruppu and Lehman (2016) (and also with Miller and O'Leary, 1987; 1994; Laughlin, 1995; Gray et al., 2014) that stakeholders' perceptions are influenced by an accepted, or generally agreed upon, form of discourse. Our SP model conveys this view by framing perceptions of financial reporting change as being constructed and manageable through the influence of change factors. This is expressed in proposition 4.2 of FRC (2016) regarding communication power. Such a view implies there is no truth or objectivity (with respect to stakeholders' perceptions) that is independent of the power of discourse (Lehman, 2013, p. 233). In this sense, we concur with the relevance of Habermas' (1987) communicative approach "to illuminate the role of the public sphere in transmitting information throughout the community" (Kuruppu and Lehman, 2016, p. 317).

However, stakeholders' perceptions of financial reporting change should be recognized as more than the result of prevailing discourse. Average knowledgeable persons in financial reporting (such as some specific stakeholders) have their own constructed and critical opinion of a change initiative. Thus, we recognize the role of discourse and of the need for critical accountability. We maintain that the SP framework is a useful tool for promoting debate about the fairness and justice of the process of effecting financial reporting change.

\section{Holistic and Contextualized Approach - Call for Interpretative and Critical Research}

The basic premise of the SP model is that direct engagement with "targets" of change stakeholders - is needed. Engagement should be seen as a way of achieving a holistically and contextualized understanding of stakeholders' perceptions of financial reporting change. Consistent with O'Dwyer (2005), we hold that perceptions of accounting change involve complex phenomena which cannot be studied in isolation from organisational, social and institutional contexts. The 
complexity of research on perceptions is acknowledged widely. Spivey et al. (2010, pp.251-52), for example, were adamant that

... there is a growing consensus that perceptual processing is not discrete. Most current research on perception challenges traditional stage-based models that assume serial and discrete processing... A majority of perception researchers seem to agree that real-time perception is a highly parallel, distributed, and interactive process. This assumption is also broadly accepted in neuroscience research.

Parker (2012, pp.65-67) argued that exposure to stakeholders was relevant because it would "... reveal the multiple interpretations and social constructions which stakeholders apply to accounting scenarios and processes." Nonetheless, recognition of the importance of obtaining in-depth understanding of stakeholders' perceptions does not imply that we consider "everything else secondary", as Kuruppu and Lehman (2016, p.316) aver. As with Parker (2012, p.67), we consider that it "can no longer simply be presumed that these constituents will be generally served and find their own way to what may be relevant to their concerns."

Kuruppu and Lehman (2016, p.317) were concerned too that "Change is unlikely and will be unable to broaden horizons without a holistic approach." We expressed concurrence with this point of view as follows:

The need for theory development in accounting has long been recognized. Laughlin (1995) claimed that accounting theory will never have an unquestionable and guaranteed theory (like a theory of gravity) that is susceptible of generalizations. Because accounting is a social practice - a social science - it must be studied within broader economic, social and political contexts. Accounting is not an objectively neutral set of measurement techniques (Humphrey \& Scapens, 1996; Laughlin, 1995; Miller \& O' Leary, 1987; Miller, 1994). It must be understood in terms of "its interrelation with other projects or the social and organisational management of individual lives" (Miller \& O' Leary, 1987). (FRC, p.302, italics applied)

Thus, consistent with the entreaty of the commentators, we seek greater critical self-reflection on how global ethical and moral demands clash with local customs and values. This is important because accountability (through reasonable behaviour and/or acceptable standards) and change arise from the relationship between parties - something that is determined by the social and moral context (Gray et al., 2014). Our focus on perceptions and financial reporting change imply a need to emphasize critical self-reflection. Such a commitment is at odds with the plea of positivists for an unquestioned and objective generalized theory. Rather, we strongly assert that the SP model requires (and is in harmony with) a critical approach to research. In FRC (2016) we strongly emphasized the complexity and dynamic nature of the concept of perception and the quest for its holistic understanding, as follows: 
To develop a comprehensive understanding of individuals' change-related perceptions, different disciplinary knowledge must be combined, using multi-level analysis (micro and macro). Additionally, there is a need to focus on internal and external aspects of change, particularly the interactions between them (Sinatra, 2002). ... Campbell (2004) emphasized the relevance of change targets' perceptions of the success of change actions, noting that ' $\ldots$ what links macro-level conditions to outcomes are individuals (or group of individuals) acting at the micro-level in response to their social and institutional situations and to each other' (FRC, pp.302-303)

\section{Radical perspective}

Because we recognize the social constructive nature of financial reporting and the relevance of interpretivism, we are sympathetic to Kuruppu and Lehman's (2016) view that operationalization of the SP model demands a radical perspective - one that will challenge the conventional wisdom of financial reporting. In FRC (2016), we argued that the development of a stream of research which considers stakeholders' perceptions and dialogue with stakeholders is crucial for reshaping the conventional wisdom of financial reporting, and re-establishing taken-for-granted assumptions. ${ }^{3}$ Such a view is a hallmark of theory development.

Taking a pro-active approach involving feedback and dialogue between the change agent and the target of the changes (all stakeholders) ought to be the ultimate intended goal in re-shaping financial reporting. The targets of change (the various stakeholder groups) are faced with challenges that often hinder the success of change processes. Their insights are likely to be highly relevant for regulators who are seeking to ensure proper implementation of a new financial reporting system. On the other hand, awareness of the many potential issues concerning the various stakeholder groups also has the strength to "tease out a transitional way to think about IASB, and IFRS proposals for change", as Kuruppu and Lehman (2016, p.317) observed.

There is strong need to consider the implications of the continuously changing moral concerns of society on the SP model, as Kuruppu and Lehman $(2016$, p.318) suggest. We highly recommended the need for longitudinal studies, and a fundamental interest in applying the SP model to different national contexts, over time. As acknowledged earlier, perceptions and change are dynamic and evolving phenomena. Thus, the operationalization of the SP model at regular intervals over time is essential for proper monitoring and reassessment of financial reporting change and adaptation. Such operationalizations will also help to anticipate new issues that are capable of complementing and

\footnotetext{
${ }^{3}$ Such a view is consistent with that of Hopper and Powell (1985, p.456, italics applied). They argued that: "It would be naive to expect that the 'fresh' approaches to accounting research will eventually constitute the single correct orthodoxy, or that they will be capable of being slotted into functional work. Their potential and case for development rather lies in the friction and debate which they can precipitate over questionable but relatively unquestioned accounting assumptions. Employment and appreciation of perspectives widely utilized elsewhere in the social sciences may enhance a more productive dialogue between disciplines and factions. It may foster the development of accounting knowledge in new areas and it may help prevent invalid research. However, most importantly, the adoption of a particular approach is inextricably linked with certain values and beliefs about the nature of the social sciences and society."
} 
improving the model. The framework of the model may therefore serve as a conceptual guide and as a starting point for reviewing efforts to implement IFRS or IFRS-based systems.

\section{Stakeholder Selection - Loose Specification of all Stakeholder Groups}

Although Thomson (2016) suggested that the SP model be used to prompt future research, he criticized the under-specification of all legitimate stakeholder groups. We recognize this limitation. However, in FRC (2016), we introduced some debate on tentative suggestions regarding the contextual variation associated with specific stakeholders groups. We drew attention to the need for these expected contextual variations to be corroborated and improved by future applications. Thus, the targeted stakeholder groups (of users, preparers and auditors) were selected merely with a view to illustrating the relevance of contextual differences between stakeholders (p.310).

We acknowledge that our targeted selection of stakeholders (users, preparers and auditors) should not be construed as representing all legitimate stakeholders. The proposed model, as developed, can be applied to any stakeholder group, so long as interpretations of resultant findings, conclusions, and implications are made from the perspective of the targeted stakeholder group. Accordingly, if future research is to advance the interests of society and downgrade the weight attached to shareholder-centric interests, it must be clear on its targeting of potentially interested stakeholders groups (Parker, 2012; Kuruppu \& Lehman, 2016, p.318). We concur with Thomson (2016) that future applied research on the SP model should be careful to support the selection criteria used to ensure all legitimate stakeholder groups are considered.

\section{Specifying the Model}

Thomson (2016) questioned the validity of the SP model. He claimed it was unable to capture the collective perceptions of each targeted stakeholder group, and the aggregate perceptions of several stakeholder groups. He characterized our model as:

... seem[ing] to imply that the perceived value of a stakeholder group will be determined by some form of aggregation of member values. The determination of a collective stakeholder group's position is much more than the sum of the parts ... A similar problem emerges in trying to determine some aggregate national perceived value of a new financial reporting system based on the collective values of each of the targeted stakeholder groups. (p.320)

The above characterization does not reflect the intended research objective underlying the development and operationalization of the SP model. Nonetheless, we agree with the commentator on the problems and difficulties of measurement, aggregation and consolidation of an individual's perceptions. We do not promote quantitative goals. 
Thomson (2016) also claimed that the SP model overlooked the basic principles of model building because it ignored the interdependencies between factors in the model. We acknowledge that evaluation of SP is likely to be difficult. Nonetheless, we do not concur that the solution is to ignore the perceived value of stakeholders in the model. FRC (2016) makes a start at introducing the construct of stakeholder perceptions in the context of IFRS/IFRS-based accounting standards, by exploring important explanatory factors. We agree there is much to learn about how any perception is formed and developed. There are many shortcomings in contemporary understanding of human perception and change processes. These must be addressed from a variety of conceptual and disciplinary perspectives. FRC (2016) was mainly concerned with providing readers with an in-depth understanding of SP, rather than seeking quantitative measures or exploring complex relations among the factors in the model. ${ }^{4}$

Thomson (2016, p. 321) provides a (possibly back-handed) complement in contending that our model represents "a step along other well-trodden inter-disciplinary paths." Many paths in research across all disciplines, are "well-trodden" and should not be regarded as objectionable. His claim that the theory borrowing approach is unsuitable because it lacks a fundamental methodological coherence, is contestable too. We are undeterred in advocating the relevance of this qualitative approach to explore stakeholders' perceptions of financial reporting change. The strength of the SP model rests on its interpretative/qualitative operationalization, and its capacity to extend theory. Future qualitative research needs to operationalize and capture the complex facets and dynamic nature of the SP model.

\section{Concluding Remarks}

The commentators seem to agree that the initial SP framework has merit; and they concur about the need for future research to conceptualize the model's dynamic and complex nature. We submit that improved understanding of how stakeholders perceive financial reporting change will generate beneficial and deep insights to whether, and if so how, those changes are accepted and/or resisted. This is essential groundwork for predicting the likely success of financial reporting change; and to "inform the contested process" (Thomson, 2016, p.320). We believe that the operationalization of such a framework, and future research on stakeholders' perceptions, will challenge the conventional wisdom of financial reporting.

Our response aligns with the suggestions of Kuruppu and Lehman (2016) that the operationalization of the SP model demands adoption of an interpretative approach. The

\footnotetext{
${ }^{4}$ Parker $(2012$, p.59) highlighted the risk of methodological rigor in qualitative research as follows: “...qualititative research can run the risk of obsessive concern with methodological issues to the potential detriment of their attention to other dimensions of the research process and its intended outcomes. Otherwise they themselves remain open to the risk of goal displacement, whereby the means of research become ends in themselves."
} 
clarifications we have provided of the methodological foundation and central intent of FRC (2016), and of the SP model, also answers the main matters raised by Thomson (2016). The succinct development of ideas in FRC (2016) was due to the word length constraints of a scholarly paper. The concerns of the commentators have helped help to clarify the need to develop interpretative/critical qualitative studies that consider different contexts, cultures, stakeholders and periods of time. Both commentaries should foster fruitful debate and future research in this area, and help to operationalize and propagate the SP model.

When fully developed, the SP model will provide a highly useful theoretical tool to assist research on stakeholders' views regarding financial reporting reforms. The model will also have strong relevance and pragmatic value for the practice of financial reporting.

\section{References}

Armstrong, P. (2008). Calling out for more: Comment on the future of interpretive accounting research. Critical Perspectives on Accounting, 19, 867-879.

Elharidy, A. M., Nicholson, B., \& Scapens, R. W. (2008). Using grounded theory in interpretive management accounting research. Qualitative Research in Accounting \& Management, 5(2), 139-155.

Fontes, A., Rodrigues, L. L., \& Craig, R. (2016). A theoretical model of stakeholder perceptions of a new financial reporting system. Accounting Forum, 40(4), 300-315.

Gray, R., Brennan, A., \& Malpas, J. (2014). New accounts: Towards a reframing of social accounting. Accounting Forum, 38 (4), 258-273.

Gurd, B. (2008). Structuration and middle-range theory - A case study of accounting during organizational change from different theoretical perspectives. Critical Perspectives on Accounting, 19, 523-543.

Habermas, J. (1987). The Theory of Communicative Action: Volume 2. Lifeworld and System: A Critique of Functionalist Reason. Boston Beacon Press.

Hopper, T., \& Powell, A. (1995). Making Sense of Research into Organizational and Social aspects of Management Accounting: A Review of its underlying assumptions. Journal of Management Studies, 22(5), 429-465.

Joannidès, V., \& Berland, N. (2008). Reactions to reading "Remaining consistent with method? An analysis of grounded theory research in accounting": A comment on Gurd. Qualitative Research in Accounting \& Management, 5(3), 253-261.

Kuruppu, S. \& Lehman, G. (2006).Commentary: A theoretical model of stakeholder perceptions of a new financial reporting system, Accounting Forum, 40(4), 319-321. 
Laughlin, R. (1995). Empirical research in accounting: Alternative approaches and a case for middlerange thinking, Accounting. Auditing \& Accountability Journal, 8(1), 63-87.

Miller, P., \& O' Leary, T. (1987). Accounting and the construction of the governable person. Accounting, Organizations and Society, 12(3), 235-265.

Miller, P., \& O' Leary, T. (1994). Accounting, 'economic citizenship', and the spatial reordering of manufacture. Accounting, Organizations and Society, 19(1),15-43.

O'Dwyer. B., Unerman, J., \& Bradley, J. (2005). Perception on the emergence and future development of corporate social disclosure in Ireland - Engaging voices of non-governmental organizations. Accounting, Auditing \& Accountability Journal, 18(1), 14-43.

Oswick, C., Fleming, P., \& Hanlon, G. (2011). From borrowing to blending: Rethinking the process of organizational theory building. Academy of Management Review, 36(2), 318-337.

Parker, L.D. (2012). Qualitative management accounting research: Assessing deliverables and relevance. Critical Perspectives on Accounting, 23(1), 54-70.

Spivey, M.J., Dale, R., Knoblich, G., \& Grosjean, M. (2010). Do curved reaching movements emerge from competing perceptions? A reply to van der Wel et al. (2009). Journal of Experimental Psychology Human Perception \& Performance, 36(1), 251-254.

Thomson, I. (2016). Commentary: A proposal for theoretical models of stakeholder perceptions of a new financial reporting system. Accounting Forum, 40(4), 316-318.

Vaivio, J. (2008). Qualitative management accounting research: rationale, pitfalls and potential. Qualitative Research in Accounting \& Management, 5(1), 64-86. 